\title{
QUEEN'S
UNIVERSITY
BELFAST
}

\section{Uptake of cadmium from an experimentally contaminated calcareous soil by arbuscular mycorrhizal maize (Zea mays L.)}

Chen, B. D., Liu, Y., Shen, H., Li, X. L., \& Christie, P. (2004). Uptake of cadmium from an experimentally contaminated calcareous soil by arbuscular mycorrhizal maize (Zea mays L.). Mycorrhiza, 14(6), $347-354$. https://doi.org/10.1007/s00572-003-0281-2

\section{Published in:}

Mycorrhiza

Queen's University Belfast - Research Portal:

Link to publication record in Queen's University Belfast Research Portal

\section{General rights}

Copyright for the publications made accessible via the Queen's University Belfast Research Portal is retained by the author(s) and / or other copyright owners and it is a condition of accessing these publications that users recognise and abide by the legal requirements associated with these rights.

Take down policy

The Research Portal is Queen's institutional repository that provides access to Queen's research output. Every effort has been made to ensure that content in the Research Portal does not infringe any person's rights, or applicable UK laws. If you discover content in the Research Portal that you believe breaches copyright or violates any law, please contact openaccess@qub.ac.uk. 


\section{B. D. Chen · Y. Liu • H. Shen • X. L. Li • P. Christie}

\section{Uptake of cadmium from an experimentally contaminated calcareous soil by arbuscular mycorrhizal maize (Zea mays L.)}

Received: 19 December 2002 / Accepted: 24 October 2003 / Published online: 6 December 2003 (C) Springer-Verlag 2003

\begin{abstract}
We investigated uptake of Cd by arbuscular mycorrhizal (AM) maize inoculated with Glomus mosseae from a low-P sandy calcareous soil in two glasshouse experiments. Plants grew in pots containing two compartments, one for root and hyphal growth and one for hyphal development only. Three levels of $\mathrm{Cd}(0,25$ and $\left.100 \mathrm{mg} \mathrm{kg}^{-1}\right)$ and two of $\mathrm{P}\left(20\right.$ and $\left.60 \mathrm{mg} \mathrm{kg}^{-1}\right)$ were applied separately to the two compartments to assess hyphal uptake of $\mathrm{Cd}$. Neither $\mathrm{Cd}$ nor $\mathrm{P}$ addition inhibited root colonization by the AM fungus, but $\mathrm{Cd}$ depressed plant biomass. Mycorrhizal colonization, $\mathrm{P}$ addition and increasing added $\mathrm{Cd}$ level led to lower $\mathrm{Cd}$ partitioning to the shoots. Plant P uptake was enhanced by mycorrhizal colonization at all $\mathrm{Cd}$ levels studied. When $\mathrm{Cd}$ was added to the plant compartment and $\mathrm{P}$ to the hyphal compartment, plant biomass increased with AM colonization and the mycorrhizal effect was more pronounced with increasing $\mathrm{Cd}$ addition. When $\mathrm{P}$ was added to the plant compartment and $\mathrm{Cd}$ to the hyphal compartment, plant biomass was little affected by AM colonization, but shoot $\mathrm{Cd}$ uptake was increased by colonization at the low $\mathrm{Cd}$ addition rate $\left(25 \mathrm{mg} \mathrm{kg}^{-1}\right)$ and lowered at the higher $\mathrm{Cd}$ rate $\left(100 \mathrm{mg} \mathrm{kg}^{-1}\right)$ but with no difference in root $\mathrm{Cd}$ uptake. These effects may have been due to immobilization of $\mathrm{Cd}$ by the fungal mycelium or effects of the AM
\end{abstract}

B. D. Chen · Y. Liu · H. Shen · X. L. Li (

Department of Plant Nutrition,

China Agricultural University,

2 Yuanmingyuan Road, 100094 Beijing, China

e-mail: lixl@cau.edu.cn

Tel.: +86-10-62891325

Fax: +86-10-62891016

P. Christie

Agricultural and Environmental Science Department,

Queen's University Belfast,

Newforge Lane, Belfast, BT9 5PX, UK

Present address:

B. D. Chen, Research Centre for Eco-Environmental Sciences,

Department of Soil Environmental Science,

Chinese Academy of Sciences,

100085 Beijing, China fungus on rhizosphere physicochemical conditions and are discussed in relation to possible phytostabilization of contaminated sites by AM plants.

Keywords Cadmium contamination $\cdot$ Phosphorus nutrition · Soil remediation · Phytostabilization · Arbuscular mycorrhiza

\section{Introduction}

Cd is a potentially phytotoxic heavy metal (di Toppi and Gabbrielli 1999). It is released into the environment by various industrial and agricultural activities including mining, metal smelting and application of sewage sludge to agricultural land (Nriagu and Pacyna 1988; Chen et al. 1999), sometimes resulting in accumulation of the metal in soils. Excessive $\mathrm{Cd}$ levels represent a threat to soil productivity and ecosystem stability, and also to human and animal health due to $\mathrm{Cd}$ accumulation in food chains (Jackson and Alloway 1991). There is therefore considerable interest in management of $\mathrm{Cd}$ in plant-soil systems and in strategies for remediation of Cd-contaminated soils or improving plant tolerance to $\mathrm{Cd}$ contamination.

It is well known that arbuscular mycorrhizal (AM) fungi are widely distributed in natural and agricultural ecosystems (Harley 1989). Although the initial plant colonizers of heavy metal-contaminated sites are often species tolerant to extreme conditions and tend to be nonmycorrhizal (Shetty et al. 1994), they may increase soil organic matter content, modify the soil microclimate and promote conditions conducive to the establishment of species with stronger mycorrhizal dependence (Leyval et al. 1997). Mycorrhizas have recently been reported in plants growing on heavy metal-contaminated sites (Shetty et al. 1995; Weissenhorn and Leyval 1995; Pawlowska et al. 1996; Chaudhry et al. 1999), and metal-tolerant fungal strains have been isolated (Griffioen 1994; Weissenhorn et al. 1993, 1994; Hildebrandt et al. 1999). Alleviation of heavy metal phytotoxicity by arbuscular mycorrhiza has been indicated in several studies (Schüepp et al. 1987; 
Heggo et al. 1990; Zhu et al. 2001; Chen et al. 2003). The AM fungi may act indirectly, for example by enhancing plant $\mathrm{P}$ nutrition and increasing plant growth with a resulting dilution effect of the metal in the host plant, or directly by binding of the metal to the fungal mycelium and immobilization in the rhizosphere or the roots (Galli et al. 1994; Joner et al. 2000; Chen et al. 2001). Nonmycorrhizal metal hyperaccumulators may thus be suitable for phytoremediation of contaminated sites while mycorrhizal colonizers may be more useful for phytostabilization of heavy metals in the field.

Using a compartmented pot system, Joner and Leyval (1997) demonstrated that ${ }^{109} \mathrm{Cd}$ added to the hyphal compartment was adsorbed by extraradical hyphae and subsequently transported to plant roots, but transfer from fungus to plants was restricted by fungal immobilization. Weissenhorn et al. (1993) demonstrated stronger tolerance to $\mathrm{Cd}$ in $\mathrm{AM}$ fungal strains isolated from heavy metal-polluted soils. The potential use of AM fungi in remediation programs for metal-contaminated ecosystems has recently been proposed (Vangronsveld et al. 1996; Khan et al. 2000; Leyval et al. 2002). However, more information is required on the mechanisms involved in mycorrhiza-mediated uptake of $\mathrm{Cd}$ by plants in contaminated soils and the effects of soil factors such as $\mathrm{P}$ supply.

This paper describes two glasshouse experiments carried out to investigate the mycorrhizal effects on plant $\mathrm{P}$ and $\mathrm{Cd}$ uptake. Plexiglas pots were separated with nylon net of 30- $\mu \mathrm{m}$ mesh size into two compartments for plant growth and hyphal development. Additions of $\mathrm{Cd}$ and $\mathrm{P}$ were made differentially to the two compartments to avoid direct interactions between the two elements. In the first experiment $\mathrm{Cd}$ was added to the plant compartment at three rates $(0,25$ or $100 \mathrm{mg} \mathrm{Cd} \mathrm{kg} \mathrm{soil),} \mathrm{and} \mathrm{two}$ levels of $\mathrm{P}$ (20 or $60 \mathrm{mg} \mathrm{P} \mathrm{kg}^{-1}$ soil) were added to the hyphal ${ }^{-1}$ compartment, while in the second experiment $\mathrm{Cd}$ was added to the hyphal compartment, and $\mathrm{P}$ to the plant compartment to discriminate between direct root uptake and indirect uptake of $\mathrm{P}$ and $\mathrm{Cd}$ via the external mycelium of the AM fungus.

\section{Materials and methods}

Mycorrhizal inoculum

The AM fungus Glomus mosseae (Nicol \& Gerd) Gerdemann \& Trappe was kindly provided by Professor H. G. Wang of the Institute of Plant Nutrition and Fertilizers, Chinese Academy of Agricultural Sciences. The fungus was propagated in pot culture on maize plants grown in a sandy soil for 10 weeks. Inoculum from pot culture was a mixture of spores, mycelium, sandy soil and maize root fragments containing approximately 1,000 spores per $100 \mathrm{~g}$.

\section{Host plants}

Seeds of maize ( Zea mays L. cv. ND108) were surface sterilized in a $10 \%(\mathrm{v} / \mathrm{v})$ solution of hydrogen peroxide for $10 \mathrm{~min}$ then immersed in deionised water for $6 \mathrm{~h}$. They were pre-germinated on moist filter paper overnight at $25^{\circ} \mathrm{C}$. The pre-germinated seeds were selected for uniformity of size before sowing.

Calcareous soil

A calcareous sandy soil of low nutrient status was collected from the vicinity of Lugouqiao, Fengtai district, Beijing. The soil had the following properties (dry matter basis): $\mathrm{pH}$ (soil:water ratio 1:2.5) 8.67, $0.30 \%$ organic matter, $0.018 \%$ Kjeldahl-N, $3.4 \mathrm{mg} \mathrm{kg}^{-1}$ of $0.5 \mathrm{~mol} \mathrm{l}^{-1} \mathrm{NaHCO}_{3}$-extractable P (Olsen et al. 1954; Murphy and Riley 1962), and $33.6 \mathrm{mg} \mathrm{kg}^{-1}$ of $1 \mathrm{~mol} \mathrm{l}^{-1} \mathrm{NH}_{4} \mathrm{OAc}$-exchangeable K. Soil-extractable trace element concentrations were: $4.96 \mathrm{mg} \mathrm{kg}^{-1}$ $\mathrm{Fe}, 4.15 \mathrm{mg} \mathrm{kg}^{-1} \mathrm{Mn}, 0.28 \mathrm{mg} \mathrm{kg}^{-1} \mathrm{Cu}, 0.48 \mathrm{mg} \mathrm{kg}^{-1} \mathrm{Zn}$, and $0.06 \mathrm{mg} \mathrm{kg}^{-1} \mathrm{Cd}$. Soil metals were extracted with a $5 \mathrm{mmol} \mathrm{l}^{-1}$ diethylene triamine pentaacetic acid- $10 \mathrm{mmol} \mathrm{l}^{-1} \mathrm{CaCl}_{2}-0.1 \mathrm{~mol} \mathrm{l}^{-1}$ triethanolamine solution adjusted to $\mathrm{pH} 7.30$ (Lindsay and Norvell 1978) and metal concentrations were determined using an atomic absorption spectrophotometer (Perkin Elmer Model 2100). Soil was passed through a $1-\mathrm{mm}$ sieve, sterilized by autoclaving at $120^{\circ} \mathrm{C}$ for $2 \mathrm{~h}$ and then air-dried.

\section{Experimental procedure}

Plexiglas pots had two compartments of equal volume separated by nylon net of $30-\mu \mathrm{m}$ mesh size to allow penetration by hyphae but not by roots. One compartment was for plant (and hyphal) growth and the other for hyphal growth only. The pots were rectangular boxes $15 \mathrm{~cm}$ high, $10 \mathrm{~cm}$ deep and $10 \mathrm{~cm}$ wide.

In both experiments there were three $\mathrm{Cd}$ addition levels $(0,25$

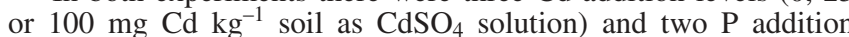
levels (20 and $60 \mathrm{mg} \mathrm{P} \mathrm{kg}^{-1}$ soil as $\mathrm{KH}_{2} \mathrm{PO}_{4}$ solution). Maize plants were inoculated with the $\mathrm{AM}$ fungus $G$. mosseae at each $\mathrm{Cd}$ and $\mathrm{P}$ addition rate and uninoculated controls were included. Thus, there were 12 treatments with four replicates giving a total of 48 pots in each experiment. All treatments received mineral nutrients applied in solution to each compartment at rates of $300 \mathrm{mg} \mathrm{N}\left(\mathrm{NH}_{4} \mathrm{NO}_{3}\right)$, $20 \mathrm{mg} \mathrm{P}\left(\mathrm{KH}_{2} \mathrm{PO}_{4}\right.$ : only to compartments with no $\mathrm{P}$ addition treatments) and $200 \mathrm{mg} \mathrm{K}\left(\mathrm{K}_{2} \mathrm{SO}_{4}\right) \mathrm{kg}^{-1}$ soil as a basal application.

Each plant compartment contained $800 \mathrm{~g}$ soil and the hyphal compartment contained $900 \mathrm{~g}$ soil. Inoculated treatments received $40 \mathrm{~g}$ of inoculum, while uninoculated plants received the same weight of sterilized inoculum together with a filtrate $(0.25 \mu \mathrm{m}$ pore size) of unsterilized soil to provide a similar microflora except for the absence of the mycorrhizal fungus. The inoculum was thoroughly mixed with the $800 \mathrm{~g}$ of fertilized soil and the soil was then placed in the plant compartment. Four selected pregerminated maize seeds were sown in the plant compartment of each pot and thinned to two plants 7 days after seedling emergence. Soil moisture content was adjusted regularly to $\sim 70 \%$ water holding capacity with deionized water during the course of the experiments.

The experiments were conducted in the glasshouse of the Department of Plant Nutrition, China Agricultural University, and the plants grew for 7 weeks from 22 April 2001 to 9 June 2001 without supplementary illumination under a daytime temperature range of $20-30^{\circ} \mathrm{C}$ and a night temperature range of $15-20^{\circ} \mathrm{C}$.

\section{Harvest and chemical analysis}

Shoots and roots were harvested separately. Samples were carefully washed with tap water and then deionised water. Sub-samples of fresh roots were collected for determination of root colonization rate by the AM fungus. The dry weights of leaves, stems and roots were determined after oven drying at $70^{\circ} \mathrm{C}$ for $48 \mathrm{~h}$. Oven-dried sub-samples were milled to pass through a $0.5-\mathrm{mm}$ sieve and dry ashed at $560^{\circ} \mathrm{C}$ for multi-element analysis by inductively coupled plasma-atomic emission spectroscopy (ICP-AES; Perkin Elmer Optima 3300DV) (Sahrawat et al. 2002; Sun et al. 2000).

Soil $\mathrm{pH}$ was measured with a $\mathrm{pH}$ meter using a soil:water ratio of 1:2.5. Root samples for assessing root colonization were 
prepared using the acid fuchsin staining-grid intersect method (Kormanik et al. 1979; Giovannetti and Mosse 1980).

Statistical analysis

Root colonization data of mycorrhizal treatments were tested by two-way ANOVA to compare $\mathrm{P}$ and Cd levels, and other variables by three-way ANOVA to compare mycorrhizal status and $\mathrm{P}$ and $\mathrm{Cd}$ levels using GenStat for PC/Windows Release 6.1 (Payne 2002).

\section{Results}

\section{Experiment 1}

\section{Mycorrhizal colonization}

No root infection was detected in uninoculated plants but roots of inoculated plants were extensively mycorrhizal, with the mean proportion of root length colonized ranging from 55 to $71 \%$ (Table 1). There was little effect of $\mathrm{Cd}$ addition level to the plant compartment on root colonization rate at the lower $\mathrm{P}$ level in the hyphal compartment. At the higher $\mathrm{P}$ level, root colonization was depressed to $55 \%$ at the lower Cd level $\left(25 \mathrm{mg} \mathrm{kg}^{-1}\right)$ compared with controls receiving no $\mathrm{Cd}$ and increased to $71 \%$ at the higher $\mathrm{Cd}$ addition level of $100 \mathrm{mg} \mathrm{kg}^{-1}$. P addition to the hyphal compartment had no effect on mycorrhizal colonization rate (Table 1).

\section{Shoot and root biomass}

Mycorrhizal colonization led to significantly higher shoot biomass $(P<0.001)$ compared with non-mycorrhizal maize but had no effect on root biomass (Table 1). The $\mathrm{P}$ level in the hyphal compartment had no effect on shoot or root biomass, but a small interaction in root biomass occurred between colonization and $\mathrm{P}$ level $(P<0.05)$ because root biomass tended to be higher in mycorrhizal plants at the lower P level and the opposite trend occurred at the higher $\mathrm{P}$ level. Both shoot and root biomass decreased with increasing rate of $\mathrm{Cd}$ application to the plant compartment.

When no $\mathrm{Cd}$ was added to the plant compartment, mycorrhizal colonization led to higher shoot biomass but had no influence on root biomass. When $25 \mathrm{mg} \mathrm{Cd} \mathrm{kg}$ was added to the plant compartment and $20 \mathrm{mg} \mathrm{P} \mathrm{kg}^{-1}$ to the hyphal compartment, both shoot and root yields
Table 1 Mean root colonization (percentage of root length colonized by Glomus mosseae), shoot and root biomass [g dry matter (DM) pot $^{-1}$ ], shoot $\mathrm{P}$ and Cd uptake $\left(\mathrm{mg} \mathrm{pot}^{-1}\right)$ and ratio of shoot Cd uptake:root Cd uptake ( $S: R$ Cd uptake) of maize plants in experiment 1 with three Cd levels $\left[0 \mathrm{mg} \mathrm{Cd} \mathrm{kg}^{-1}(C d 0), 25 \mathrm{mg} \mathrm{Cd}\right.$ $\mathrm{kg}^{-1}(C d 25)$ and $100 \mathrm{mg} \mathrm{Cd} \mathrm{kg}{ }^{-1}(C d$ 100)] added to the plant compartment and two levels of $\mathrm{P}\left[20 \mathrm{mg} \mathrm{P} \mathrm{kg}^{-1}(P 20)\right.$ and $60 \mathrm{mg} \mathrm{P}$
$\left.\mathrm{kg}^{-1}(P 60)\right]$ added to the hyphal compartment of mycorrhizal [inoculated with the arbuscular mycorrhizal (AM) fungus $G$. mosseae $]$ and non-mycorrhizal plants. Significance of $F$-ratios by two-way ANOVA for root colonization of mycorrhizal plants and by three-way ANOVA for other variables. n.d. Not determined (because $\mathrm{Cd}$ concentrations in plants receiving no added $\mathrm{Cd}$ were below the detection limit)

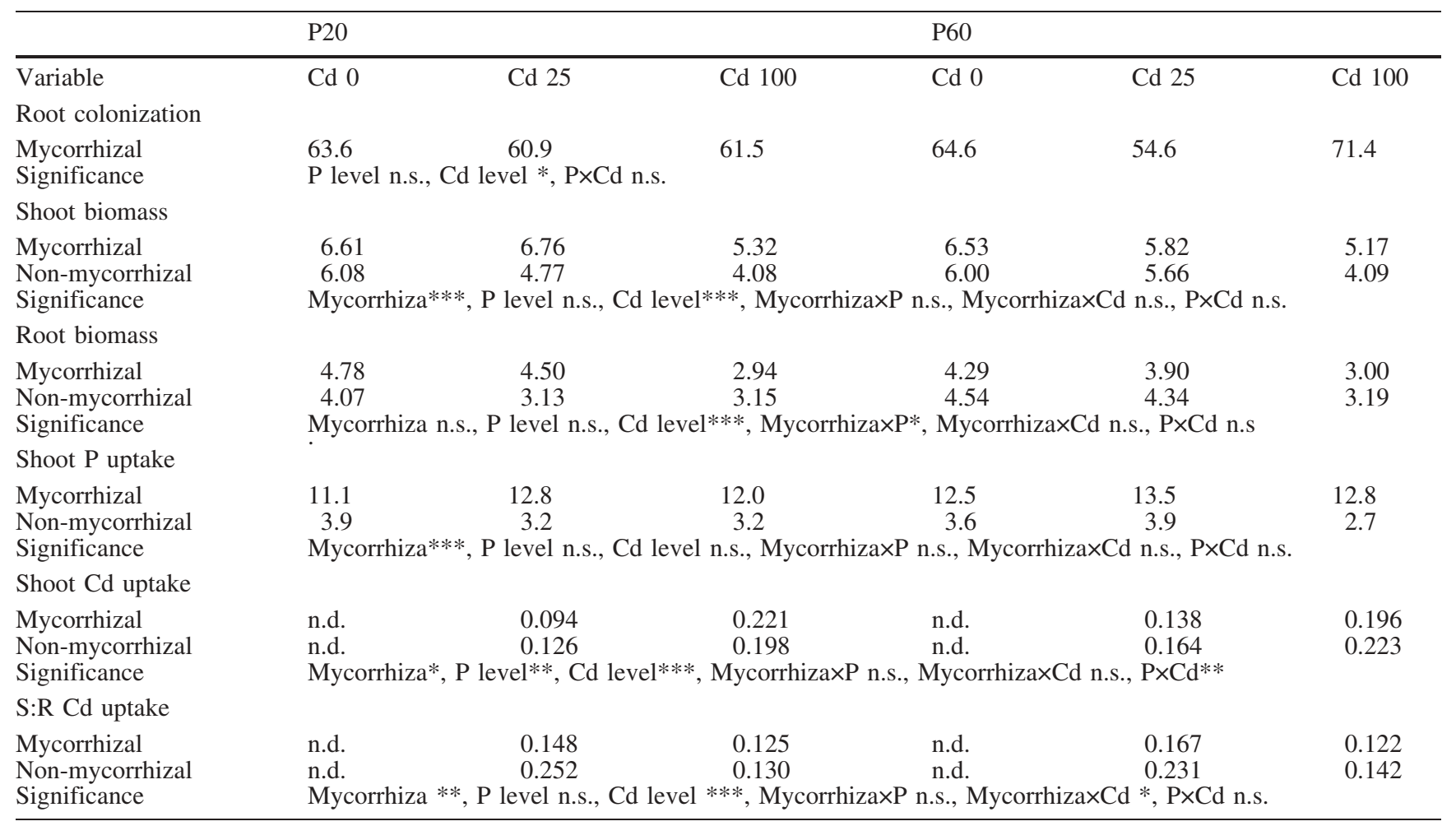

*** $P<0.001, * * P<0.01, * P<0.05$, n.s. not significant 


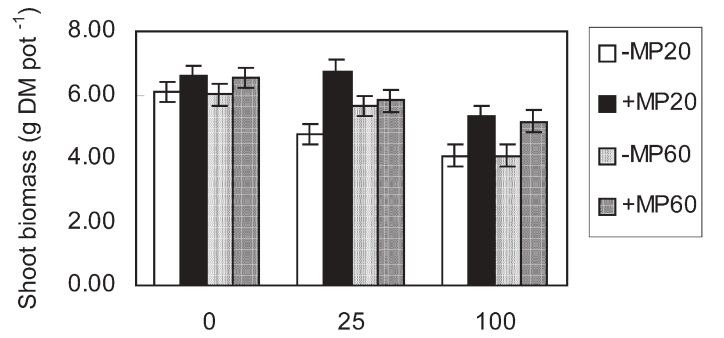

a

Cd addition level $\left(\mathrm{mg} \mathrm{kg}^{-1}\right)$

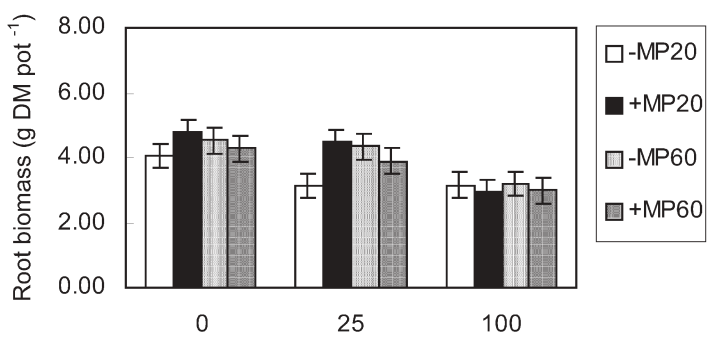

b

$\mathrm{Cd}$ addition level $\left(\mathrm{mg} \mathrm{kg}^{-1}\right)$

Fig. 1 Shoot (a) and root (b) biomass of maize plants in experiment 1 with three $\mathrm{Cd}$ levels added to the plant compartment and two levels of $\mathrm{P}$ [20 mg P kg-1 (P20) and $60 \mathrm{mg} \mathrm{P} \mathrm{kg}^{-1}$ (P60)] added to the hyphal compartment of non-mycorrhizal $(-M)$ and mycorrhizal $[+M$; inoculated with the arbuscular mycorrhizal (AM) fungus $G$. mosseae $]$ plants. Bars indicate \pm 1 SEM as estimated from three-way ANOVA

increased with mycorrhizal colonization, while plant growth was unaffected at the $\mathrm{P}$ addition rate of $60 \mathrm{mg}$ $\mathrm{kg}^{-1}$. At the Cd addition level of $100 \mathrm{mg} \mathrm{kg}^{-1}$ in the plant compartment, shoot biomass was substantially increased but root biomass decreased with mycorrhizal colonization and there was no effect of $\mathrm{P}$ addition treatment (Fig. 1).

Maize plants exhibited severe symptoms of Cd toxicity with chlorosis and withering of old leaves and stunting of the plants, especially at the higher $\mathrm{Cd}$ addition level of $100 \mathrm{mg} \mathrm{kg} \mathrm{kg}^{-1}$, and these symptoms appeared to be alleviated by mycorrhizal colonization. Typical P deficiency symptoms were also observed in plants from all uninoculated treatments, but not in any of the mycorrhizal plants.

\section{Shoot P uptake}

Shoot $\mathrm{P}$ uptake was significantly higher with mycorrhizal colonization $(P<0.001)$, but was unaffected by $\mathrm{P}$ addition treatment irrespective of $\mathrm{Cd}$ addition level (Table 1). Root $\mathrm{P}$ uptake decreased with the increasing $\mathrm{Cd}$ addition level but shoot $\mathrm{P}$ uptake was unaffected (Fig. 2).

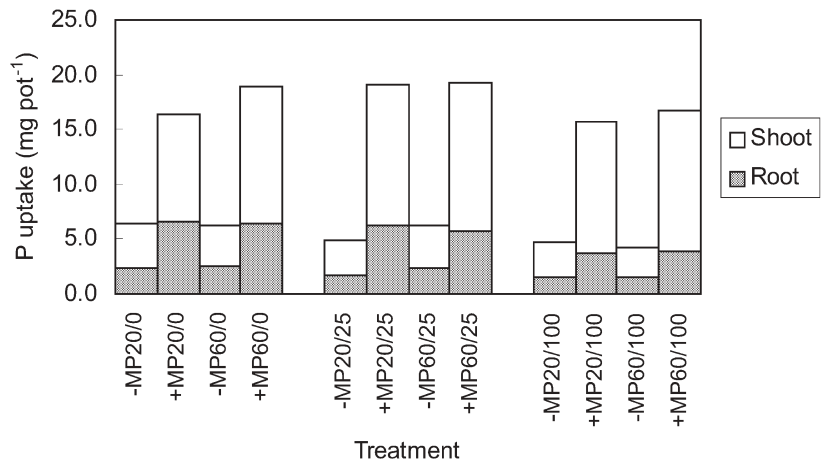

Fig. 2 Shoot and root $\mathrm{P}$ uptake of maize plants in experiment 1 with three Cd levels $\left(0,25\right.$ and $\left.100 \mathrm{mg} \mathrm{Cd} \mathrm{kg}^{-1}\right)$ added to the plant compartment and two P levels (P20 and P60) added to the hyphal compartment of $-\mathrm{M}$ and $+\mathrm{M}$ (inoculated with the AM fungus $G$. mosseae) plants. SEMs as estimated from three-way ANOVA were 0.70 and $0.44 \mathrm{mg} \mathrm{P} \mathrm{pot}^{-1}$ for shoots and roots, respectively. For abbreviations, see Fig. 1

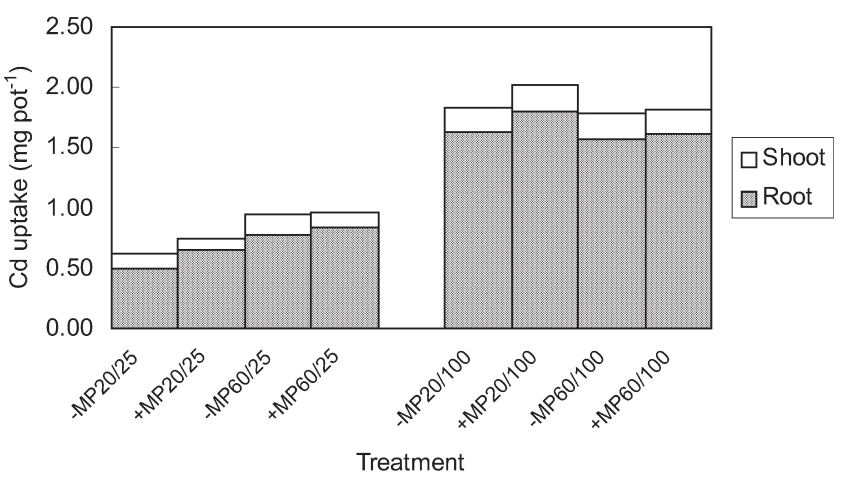

Fig. 3 Shoot and root $\mathrm{Cd}$ uptake by maize plants in experiment 1 with two levels of $\mathrm{Cd}\left(25\right.$ and $\left.100 \mathrm{mg} \mathrm{Cd} \mathrm{kg}{ }^{-1}\right)$ added to the plant compartment and two levels of P (P20 and P60) added to the hyphal compartment of $-\mathrm{M}$ and $+\mathrm{M}$ (inoculated with the AM fungus $G$. mosseae) plants. SEMs as estimated from three-way ANOVA were 0.010 and $0.107 \mathrm{mg} \mathrm{Cd} \mathrm{pot}^{-1}$ for shoots and roots, respectively. For abbreviations, see Fig. 1

\section{Shoot Cd uptake}

Shoot $\mathrm{Cd}$ uptake increased greatly with increasing $\mathrm{Cd}$ addition levels to the plant compartment $(P<0.001)$. Shoot $\mathrm{Cd}$ uptake was generally higher than root uptake in the controls receiving no added $\mathrm{Cd}$. Plants receiving $25 \mathrm{mg}$ $\mathrm{kg}^{-1}$ added $\mathrm{Cd}$ showed lower shoot $\mathrm{Cd}$ uptake but higher root $\mathrm{Cd}$ uptake with mycorrhizal colonization. $\mathrm{P}$ addition to the hyphal compartment generally resulted in higher plant Cd uptake. At the Cd addition level of $100 \mathrm{mg} \mathrm{kg}^{-1}$, neither $\mathrm{P}$ nor $\mathrm{Cd}$ addition showed any discernible influence on plant Cd uptake (Fig. 3).

Relatively less $\mathrm{Cd}$ was partitioned to the shoots at higher $\mathrm{Cd}$ addition levels as indicated by the lower shoot:root ratio of $\mathrm{Cd}$ uptake under the $100 \mathrm{mg} \mathrm{kg}^{-1} \mathrm{Cd}$ addition level compared with $25 \mathrm{mg} \mathrm{kg}^{-1}$ of added $\mathrm{Cd}$ and the zero-Cd controls. Mycorrhizal colonization was also associated with lower $\mathrm{Cd}$ partitioning to the shoots, while 
Table 2 Mean root colonization (percentage of root length colonized by $G$. mosseae), shoot and root biomass $\left(\mathrm{g} \mathrm{DM} \mathrm{pot}^{-1}\right)$, shoot $\mathrm{P}$ and Cd uptake $\left(\mathrm{mg} \mathrm{pot}^{-1}\right)$ and S:R Cd uptake of maize plants in experiment 2 with three Cd levels $(0 \mathrm{Cd}, 25 \mathrm{Cd}$ and $100 \mathrm{Cd}$ ) added to the hyphal compartment and two levels of P (P20 and P60) added to the plant compartment of mycorrhizal (inoculated with the AM fungus $G$. mosseae) and non-mycorrhizal plants. Significance of $F$-ratios by two-way ANOVA for root colonization of mycorrhizal plants and by three-way ANOVA for other variables. For abbreviations, see Table 1

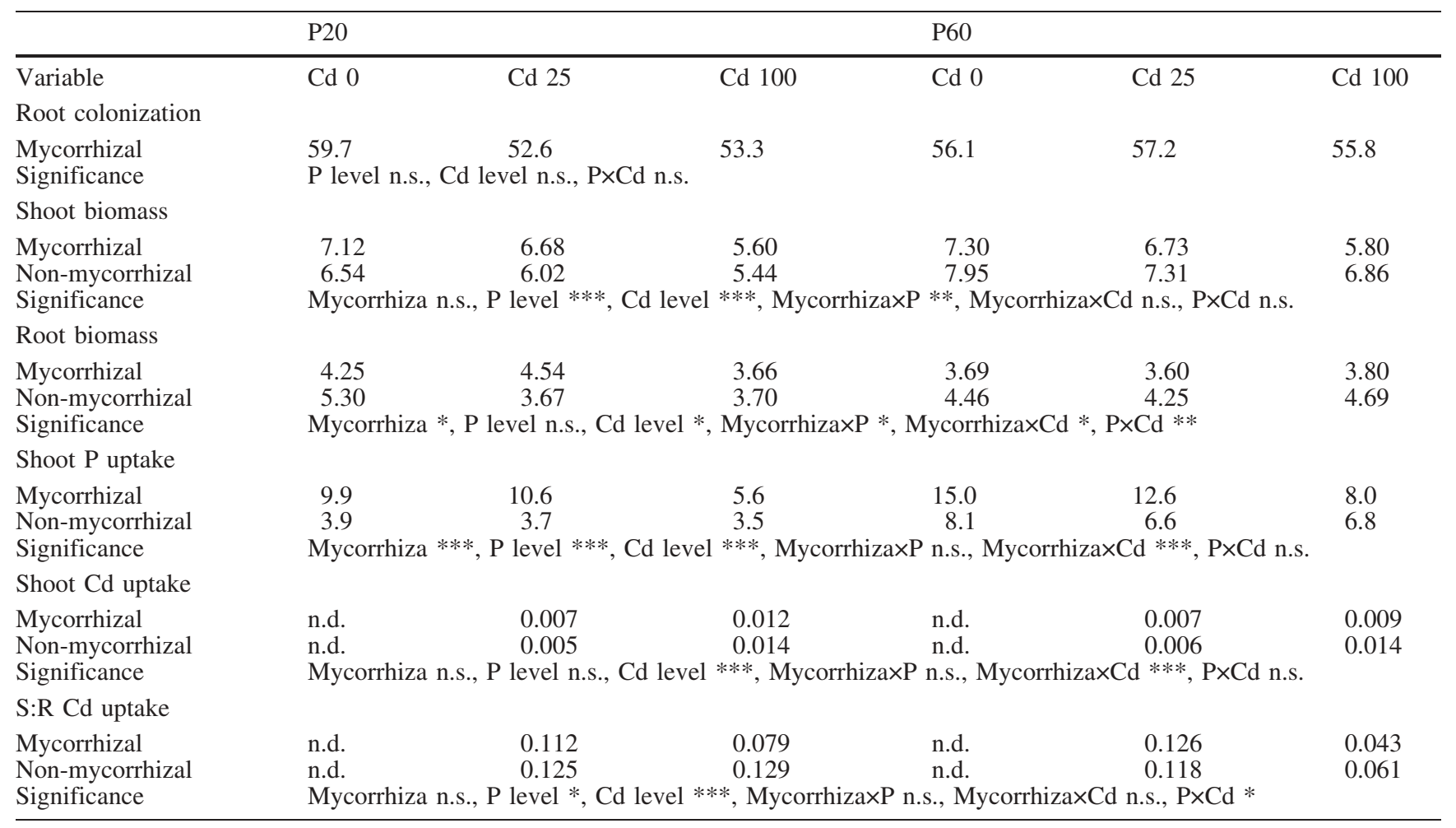

$* * * P<0.001, * * P<0.01, * P<0.05$, n.s. not significant

$\mathrm{P}$ addition had no marked effect on $\mathrm{Cd}$ partitioning in the plants (Tables 1,2).

\section{Experiment 2}

\section{Mycorrhizal colonization}

As in experiment 1 , no root infection was detected in uninoculated plants while the proportion of root length of inoculated plants colonized ranged from 53 to $60 \%$ (Table 2), and mycorrhizal colonization was unaffected by $\mathrm{Cd}$ or $\mathrm{P}$ addition treatments.

\section{Shoot and root biomass}

The plants appeared healthy compared to those in experiment 1 with no severe symptoms of chlorosis in any treatment. Shoot biomass was markedly decreased by $\mathrm{Cd}$ addition to the hyphal compartment but there was no significant difference in root biomass between the two $\mathrm{Cd}$ addition levels (Table 2). Under all $\mathrm{Cd}$ addition levels, $\mathrm{P}$ additions to the plant compartment increased the biomass of uninoculated but not of inoculated plants (Fig. 4). When no $\mathrm{Cd}$ was added to the hyphal compartment, $\mathrm{P}$
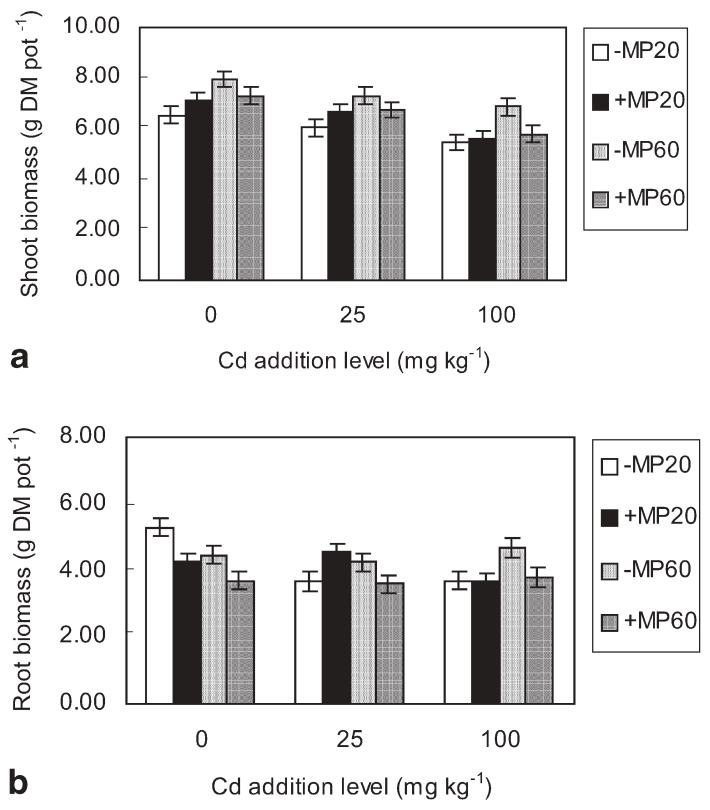

Fig. 4 Shoot (a) and root (b) biomass of maize plants in experiment 2 with three Cd levels added to the hyphal compartment and two levels of P (P20 and P60) added to the plant compartment of $-\mathrm{M}$ and $+\mathrm{M}$ (inoculated with the AM fungus $G$. mosseae) plants. Bars indicate \pm 1 SEM as estimated from three-way ANOVA 


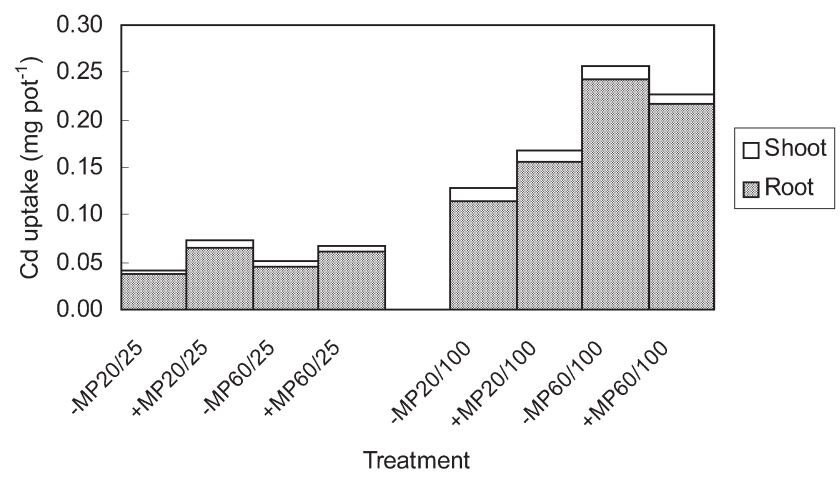

Fig. 5 Shoot and root Cd uptake by maize plants in Experiment 2 with two levels of $\mathrm{Cd}$ (25 and $100 \mathrm{mg} \mathrm{Cd} \mathrm{kg}^{-1}$ ) added to the hyphal compartment and two levels of P (P20 and P60:20 and $60 \mathrm{mg} \mathrm{P}$ $\mathrm{kg}^{-1}$ ) added to the plant compartment of non-mycorrhizal (-M) and mycorrhizal (+M: inoculated with the AM fungus $G$. mosseae) plants. SEMs as estimated from three-way ANOVA were 0.001 and $0.009 \mathrm{mg} \mathrm{Cd}$ pot $^{-1}$ for shoots and roots, respectively. For abbreviations, see Fig. 1

additions to the plant compartment depressed root biomass, while under $\mathrm{Cd}$ additions uninoculated plants had a larger root biomass at the higher $\mathrm{P}$ addition rate, with no such trends observed in inoculated plants (Fig. 4).

In general, shoot biomass was not significantly affected by mycorrhizal colonization, but at the $\mathrm{P}$ addition level of $20 \mathrm{mg} \mathrm{kg}^{-1}$ shoot biomass tended to increase with AM inoculation, with the opposite trend at the $\mathrm{P}$ addition level of $60 \mathrm{mg} \mathrm{kg}^{-1}$ (Fig. 4). On the other hand, mycorrhizal colonization led to a small but significant $(P<0.05)$ depression in root growth (Table 2).

\section{Shoot Cd uptake and hyphal contribution}

When no Cd was added to the hyphal compartment only traces of $\mathrm{Cd}$ occurred in the plants. Under the $\mathrm{Cd}$ addition level of $25 \mathrm{mg} \mathrm{kg}^{-1}, \mathrm{Cd}$ uptake by both shoots and roots was increased by mycorrhizal colonization. $\mathrm{P}$ addition showed no discernible influence on plant $\mathrm{Cd}$ uptake (Fig. 5). Under the highest $\mathrm{Cd}$ addition level of $100 \mathrm{mg}$ $\mathrm{kg}^{-1}$, shoot $\mathrm{Cd}$ uptake was lowered by mycorrhizal colonization, while root $\mathrm{Cd}$ uptake was increased by mycorrhizal colonization at the $\mathrm{P}$ addition rate of $20 \mathrm{mg}$ $\mathrm{kg}^{-1}$ in the plant compartment, but with the elevated $\mathrm{P}$ addition rate of $60 \mathrm{mg} \mathrm{kg}^{-1} \mathrm{Cd}$ uptake by both shoots and roots decreased due to mycorrhizal colonization (Fig. 5).

\section{Discussion}

High concentrations of $\mathrm{Cd}$ in the soil have been reported to inhibit mycorrhizal colonization (Gildon and Tinker 1983; Weissenhorn and Leyval 1995). Inhibitory effects of $\mathrm{P}$ fertilizer or high available $\mathrm{P}$ on AM fungal growth have also been found (e.g. Nagahashi et al. 1996). However, in the present study neither $\mathrm{Cd}$ nor $\mathrm{P}$ addition showed any negative effect on root colonization by $G$. mosseae. Relatively high root colonization rates occurred even at the highest $\mathrm{Cd}$ addition level. One possible explanation is that the plant roots were confined to a small volume of soil, so that any inhibitory effects of $\mathrm{Cd}$ or $\mathrm{P}$ on mycorrhizal colonization may have been minimized. In addition, it is possible that even the higher addition rate of $\mathrm{P}\left(60 \mathrm{mg} \mathrm{kg}{ }^{-1}\right)$ did not fully ameliorate the available P deficiency in the calcareous soil used.

The results of the first experiment indicate that positive effects of mycorrhizal colonization on plant biomass were more pronounced under conditions of $\mathrm{Cd}$ contamination. In contrast, in the second experiment mycorrhizal colonization showed no significant influence on plant biomass. At the higher P addition level of $60 \mathrm{mg}$ $\mathrm{kg}^{-1}$, plant biomass was depressed by AM colonization. On the other hand, biomass of uninoculated plants increased with $\mathrm{P}$ addition to the plant compartment. The different plant biomass results may be ascribed to the maize plants experiencing "direct" $\mathrm{Cd}$ contamination in the first experiment in contrast to the second experiment in which only a small fraction of the added $\mathrm{Cd}$ was transferred to the plants via hyphal uptake, with a correspondingly small influence on plant biomass. In addition, relatively large amounts of carbohydrates in the plants may have been allocated to establishment of the mycorrhizal association and associated fungal growth (Harris and Paul 1987; Peng et al. 1993), and this may have masked the mycorrhizal contribution to P uptake.

Numerous studies have indicated that positive effects of mycorrhizas on host plants under conditions of environmental stress might be attributable, directly or indirectly, to enhanced plant $\mathrm{P}$ nutrition. However, in our second experiment plant $\mathrm{P}$ uptake (data not shown), but not plant biomass, was increased by mycorrhizal colonization. Thus, no close relationship was found between enhanced $\mathrm{P}$ nutrition of inoculated plants and plant biomass. Mycorrhizal associations are often regarded as symbiotic systems in which host plants and mycorrhizal fungi rely upon and benefit from each other (Smith and Gianinazzi-Pearson 1988). However, the AM fungus may play the role of a plant parasite that can assist host plant nutrition and growth in some circumstances. When there is a ready supply of soil $\mathrm{P}$ for plant uptake, it may be energetically more economical for the plant to take up soil $\mathrm{P}$ directly than to take it up via the fungus and donate $\mathrm{C}$ substrates to the fungus, as reviewed by Jakobsen et al. (2002).

Under Cd contamination, both mycorrhizal colonization and $\mathrm{P}$ fertilization can decrease $\mathrm{Cd}$ partitioning to plant shoots. However, there may be differences in the underlying mechanisms besides the "dilution effect" as a result of improved plant $\mathrm{P}$ nutrition and growth. In mycorrhizal plants, binding of Cd by mycorrhizal structures may have lowered the partitioning of $\mathrm{Cd}$ to the shoots. At the $\mathrm{Cd}$ addition level of $100 \mathrm{mg} \mathrm{kg}^{-1}$ in the first experiment, the reduction in $\mathrm{Cd}$ translocation to the shoots with mycorrhizal association was less pronounced, perhaps because of toxicity from the relatively high level of added Cd. 
Li and Christie (2001) suggested that depression of heavy metal translocation to plant shoots by mycorrhiza was associated with metal immobilization by the mycorrhizal fungi. The results of the second experiment are consistent with this hypothesis. The different effects of $G$. mosseae on $\mathrm{Cd}$ uptake by maize plants under the two $\mathrm{Cd}$ addition levels indicate that soil $\mathrm{Cd}$ contamination level had an important effect on the AM fungus. At the lower contamination level, the extraradical hyphae of the mycorrhizal fungus may have absorbed $\mathrm{Cd}$ from the hyphal compartment with some $\mathrm{Cd}$ transferred to the plants, resulting in increased $\mathrm{Cd}$ uptake by mycorrhizal plants compared with uninoculated controls. When the soil was more heavily contaminated, the high $\mathrm{Cd}$ concentration may have inhibited hyphal absorption, or may have inhibited fungal physiological activities, so that $\mathrm{Cd}$ was mainly adsorbed by or bound to the fungal mycelium.

Mycorrhizal colonization may have resulted in morphological or physiological changes in the roots (Atkinson et al. 1994), with subsequent changes in the mycorrhizosphere and effects on metal mobility and uptake by the plants. In the second experiment, soil $\mathrm{pH}$ in the hyphal compartment of inoculated treatments was generally higher than in the corresponding uninoculated treatments (data not shown). At the elevated soil $\mathrm{pH}$ levels the mobility and availability of $\mathrm{Cd}$ may have decreased (Xian and Shokohifard 1989), resulting in lower Cd uptake by the roots or extraradical hyphae.

The present study has provided further evidence for the inhibition of heavy metal translocation from roots to shoots in AM plants and effects of AM fungi on host plants under conditions of metal contamination. Nonmycorrhizal hyperaccumulator species that translocate metals efficiently to the shoots may be useful for phytoextraction of metals from the soil, but mycorrhizal plants that minimize metal translocation to the shoots may be useful for phytostabilization of contaminated sites (Leyval et al. 2002). Mycorrhizal crop species such as maize may also be grown in moderately contaminated areas without excessive metal transfer to the grain so that the soil can still be used for agricultural production without serious contamination of the food chain. Howev$\mathrm{er}$, further work is required to establish more accurately the role of mycorrhizal fungi in soil phytostabilization.

Acknowledgements We thank the Major State Basic Research Development Program of the People's Republic of China (Project G1999011808) and the National Natural Science Foundation of China (Project 40071050) for financial support, and two anonymous referees for their very helpful comments on the manuscript.

\section{References}

Atkinson S, Berta G, Hooker JE (1994) Impact of mycorrhizal colonization on root architecture, root longevity and the formation of growth regulators. In: Gianinazzi S, Schüepp H (eds) Impact of arbuscular mycorrhizas on sustainable agriculture and natural ecosystems. Birkhäuser, Basel, pp 89-99
Chaudhry TM, Hill L, Khan AG, Kuek C (1999) Colonization of iron and zinc-contaminated dumped filter-cake waste by microbes, plants and associated mycorrhizae. In: Wong M.H, Wong JWC, Baker AJM (eds) Remediation and management of degraded land. CRC, Boca Raton, Fla., pp 275-283

Chen BD, Christie P, Li XL (2001) A modified glass bead compartment cultivation system for studies on nutrient uptake by arbuscular mycorrhiza. Chemosphere 42:185-192

Chen BD, Li XL, Tao HQ, Christie P, Wong MH (2003) The role of arbuscular mycorrhiza in zinc uptake by red clover growing in a calcareous soil spiked with various quantities of zinc. Chemosphere 50:839-846

Chen HM, Zheng CR, Tu C, Zhu YG (1999) Heavy metal pollution in soils in China: status and countermeasures. Ambio 28:130 134

Galli U, Schüepp H, Brunold C (1994) Heavy metal binding by mycorrhizal fungi. Physiol Plant 92:364-368

Gildon A, Tinker PB (1983) Interactions of vesicular-arbuscular mycorrhizal infection and heavy metals in plants. I. The effects of heavy metals on the development of vesicular-arbuscular mycorrhizas. New Phytol 95:247-261

Giovannetti M, Mosse B (1980) An evaluation of techniques for measuring vesicular-arbuscular mycorrhizal infection in roots. New Phytol 84:489-500

Griffioen WAJ (1994) Characterization of a heavy metal-tolerant endomycorrhizal fungus from the surroundings of a zinc refinery. Mycorrhiza 4:197-200

Harley JL (1989) The significance of mycorrhiza. Mycol Res 92:129-139

Harris D, Paul EA (1987) Carbon requirements of vesiculararbuscular mycorrhizae. In: Safir GR (ed) Ecophysiology of VA mycorrhizae. CRC, Boca Raton, Fla., pp 93-105

Heggo A, Angle JS, Chaney RL (1990) Effects of vesiculararbuscular mycorrhizal fungi on heavy metal uptake by soybeans. Soil Biol Biochem 22:865-869

Hildebrandt U, Kaldorf M, Bothe H (1999) The zinc violet and its colonization by arbuscular mycorrhizal fungi. J Plant Physiol 154:709-717

Jackson AP, Alloway BJ (1991) The transfer of cadmium from sewage sludge-amended soils into the edible components of food crops. Water Air Soil Pollut 57-58:873-881

Jakobsen I, Smith SE, Smith FA (2002) Function and diversity of arbuscular mycorrhizae in carbon and mineral nutrition. In: Heijden MGA van der, Sanders I (Eds) Mycorrhizal ecology. Springer, Berlin Heidelberg New York, pp 75-92

Joner EJ, Leyval C (1997) Uptake of ${ }^{109} \mathrm{Cd}$ by roots and hyphae of a Glomus mosseae / Trifolium subterraneum mycorrhiza from soil amended with high and low concentrations of cadmium. New Phytol 135:353-360

Joner EJ, Briones R, Leyval C (2000) Metal-binding capacity of arbuscular mycorrhizal mycelium. Plant Soil 226:227-234

Khan AG, Kuek C, Chaudhry TM, Khoo CS, Hayes WJ (2000) Role of plants, mycorhizae and phytochelators in heavy metal contaminated land remediation. Chemosphere 41:197-207

Kormanik PP, Bryan WC, Schultz RC (1979) Procedures and equipment for staining large numbers of plant root samples for mycorrhizal assay. Can J Microbiol 26:537-538

Leyval C, Turnau K, Haselwandter K (1997) Effect of heavy metal pollution on mycorrhizal colonization and function: physiological, ecological and applied aspects. Mycorrhiza 7:139-153

Leyval C, Joner EJ, del Val C, Haselwandter K (2002) Potential of arbuscular mycorrhizal fungi for bioremediation. In: Gianinazzi S, Schüepp H, Barea JM, Haselwandter (Eds) Mycorrhizal technology in agriculture. Birkhäuser, Basel, pp 175-186

Li XL, Christie P (2001) Changes in soil solution $\mathrm{Zn}$ and $\mathrm{pH}$ and uptake of $\mathrm{Zn}$ by arbuscular mycorrhizal red clover in $\mathrm{Zn}$ contaminated soil. Chemosphere 42:201-207

Lindsay WL, Norvell WA (1978) Development of DTPA soil test for zinc, iron, manganese and copper. Soil Sci Soc Am J 42:421-428 
Murphy J, Riley JP (1962) A modified single solution method for the determination of phosphate in natural waters. Anal Chim Acta 27:31-36

Nagahashi G, Douds DD, Abney GD (1996) Phosphorus amendment inhibits hyphal branching of the VAM fungus Gigaspora margarita directly and indirectly through its effect on root exudation. Mycorrhiza 6:403-408

Nriagu JO, Pacyna JM (1988) Quantitative assessment of worldwide contamination of air, water and soils by trace metals. Nature 333:134-139

Olsen SR, Cole CV, Watanabe FS, Dean LA (1954) Estimation of available phosphorus in soils by extraction with sodium bicarbonate. USDA Agric Circ 939:1-19

Pawlowska TE, Blaszkowski J, Ruhling A (1996) The mycorrhizal status of plants colonizing a calamine spoil mound in southern Poland. Mycorrhiza 6:499-505

Payne RW (ed) (2002) The guide to GenStat release 6.1. Part 1. Syntax and data management. GenStat Committee. VSN International, Hemel Hempstead, UK

Peng SB, Eissenstat DM, Graham JH, Williams K, Hodge NC (1993) Growth depression in mycorrhizal citrus at high phosphorus supply: Analysis of carbon costs. Plant Physiol 101:1063-1071

Sahrawat KL, Kumar GR, Rao JK (2002) Evaluation of triacid and dry ashing procedures for determining potassium, calcium, magnesium, iron, zinc, manganese, and copper in plant materials. Commun Soil Sci Plant Anal 33:95-102

Schüepp H Dehn B, Sticher H (1987) VA mycorrhiza and heavy metal stress. Angew Bot 61:85-95

Shetty PK, Hetrick BAD, Figge DAH, Schwab AP (1994) Effects of mycorrhizae and other soil microbes on revegetation of heavy metal contaminated mine spoil. Environ Pollut 86:181188
Shetty KG, Banks MK, Hetrick BAD, Schwab AP (1995) Effects of mycorrhizae and fertilizer amendments on zinc tolerance of plants. Environ Pollut 88:307-314

Smith SE, Gianinazzi-Pearson V (1988) Physiological interactions between symbionts in vesicular-arbuscular mycorrhizal plants. Annu Rev Plant Physiol Plant Mol Biol 39:221-244

Sun DH, Waters JK, Mawhinney TP (2000) Determination of thirteen common elements in food samples by inductively coupled plasma atomic emission spectrometry: Comparison of five digestion methods. J AOAC Int 83:1218-1224

Toppi LS di, Gabbrielli R (1999) Response to cadmium in higher plants. Environ Exp Bot 41:105-130

Vangronsveld J, Colpaert JV, Van Tichelen KK (1996) Reclamation of a bare industrial area contaminated by non-ferrous metals: Physico-chemical and biological evaluation of the durability of soil treatment and revegetation. Environ Pollut 94:131-140

Weissenhorn I, Leyval C (1995) Root colonization of maize by a Cd-sensitive and a Cd-toleranct Glomus mosseae and cadmium uptake in sand culture. Plant Soil 175:233-238

Weissenhorn I, Leyval C, Berthelin J (1993) Cd-tolerant arbuscular mycorrhizal (AM) fungi from heavy metal polluted soil. Plant Soil 157:247-256

Weissenhorn I, Glashoff A, Leyval C, Berthekin J (1994) Differential tolerance to $\mathrm{Cd}$ and $\mathrm{Zn}$ of arbuscular mycorrhizal (AM) fungal spores isolated from heavy metal polluted and unpolluted soils. Plant Soil 167:189-196

Xian X, Shokohifard GI (1989) Effect of pH on chemical forms and plant availability of cadmium, zinc and lead in polluted soil. Water Air Soil Pollut 45:265-273

Zhu YG, Christie P, Laidlaw AS (2001) Uptake of Zn by arbuscular mycorrhizal white clover from Zn-contaminated soil. Chemosphere 42:193-199 